is respectfully suggested, whether the contemplated law ought not to require these officers to keep a particular and separate account, accessible to the public, at each custom house, of the quantity and value of all merchandise imported, whether free of duty or subject to specific or ad valorem duties? The statistical information thus obtained would be of great importance to the manufacturing chemist, as well as to every other class of persons. The law might, with great propriety, also provide for a more prompt diffusion of the information thus obtained. Statistical facts are valuable in proportion to the promptness with which they are known. When delayed, they are more a matter of curiosity than of practical usefulness.

"A well-organized system of statistics would not only be a guide to the statesman, enabling him to legislate on the intricate subject of trade understandingly, but it would inform the merchant on the important matter of consumption and supply, and save him from the many errors into which he is liable to be led, by reason of his unavoidable ignorance in this particular. Such intelligence often, and promptly, communicated, would, in a great measure, prevent the occurrence of that scarcity and consequent enhancement of price, which so frequently takes the consumer by surprise; and on the other hand, would guard against that excessive glut and consequent ruinous reduction of prices, which have done more to involve the enterprising merchant and injure the manufacturer, than all the foreign competition that can be combined against them.'

On behalf of the Committee,

IsAaC Tysox, JR., Chairman

The remarks which this Report of the Committee on Chem. istry makes upon the effects of foreign competition, the necessity of an adequate protective tariff and the importance of a wellorganized system of statistics are as applicable to-day as they were 85 years ago.

But the principal lessons to be drawn from this early report upon industrial preparedness are contained in the Memorial which the Friends of Domestic Industry transmitted to Congress.

The thought that the only successful method of combating militarism is by means of an efficient industrialism is not lightly to be dismissed. In reflecting upon the downfall of Napoleon the Memorial asks the following momentous question:

"Has it not been a matter of common remark, since the close of the late wars, that it was not the artillery of Wellington and Blucher, nor even the noble enthusiasm of the youth of Germany, but the mightier machinery of the power-loom and spinning jenny, the splendid miracles of Arkwright and Cartwright, that sustained the cause of the alliance in all the fields of Europe for twenty-five years in succession, and finally overthrew the greatest military empire that ever existed?"

The dangers which threaten domestic industries at the conclusion of a foreign war can be illustrated no better than by the following account of what happened in the United States after the Napoleonic wars.

"Everything goes on prosperously until the war comes to a close. Within a few months after, our markets are inundated with British goods, cheaper than we can make them of equal quality, and the manufacturers are, in their turn, involved in one common ruin. It is in this way that the fluctuations incident to these distant and uncertain exchanges reach successively all the great branches of industry. The results which your memorialists have thus described are not accidental, but the regular consequences of the state of things to which they are attributed, and must continue to recur from time to time, wherever such a state of things exists.,"

In commenting to Congress upon the possibility of future occurrences of this kind, in which even the United States might be involved, the Memorial sounds an admonition which is almost prophetic.

"At this moment, the danger of such an occurrence appears to be again very imminent; but whatever may be the issue of the present crisis, it is, at all events, clearly the duty of an American statesman to suppose, and to act upon the supposition, that the country is continually liable to be drawn into war with any of the foreign powers with which we have relations. If then we look to these foreign powers for our regular supply of the ordinary comforts of life, what is to become of us during these periods of occasional hostilities, which may last three years or thirty as the quarrel happens to turn? By what miracle are we to find, at a moment's warning, resources, before unemployed, which will furnish us with substitutes for this supply? Are we to extemporize at the commencement of every war, as we did at that of the last, a set of manufacturers sufficient to meet the demand of twelve, fifteen, or, looking forward only to the end of the next five and twenty years, twenty million consumers, only to see them all shaken to their foundations by the return of peace, and sinking in one general ruin as they did before? Your memorialists can hardly imagine how an intelligent person can be so totally blind to the most obvious considerations of expediency as to counsel such a policy. They leave it with confidence to your honorable body to decide, whether it be not the duty of a prudent government to provide, by every imaginable means, against the recurrence of such widely spreading disasters; whether, were it even true, as it is not, that domestic manufactures would be, in the end, dearer than foreign ones, an annual pecuniary sacrifice of considerable extent made in this form, would not be decidedly preferable both on the score of interest and feeling, to supporting the incalculable losses and miseries of every kind produced by these convulsions."

With this final warning we must bring our citations from the Report of the Friends of Domestic Industry to a close. It would be interesting to quote more fully, but enough has been given to indicate the resemblance of conditions a century ago to those of to-day. In addition to the light which the Report throws upon the early state of our chemical and other industries, it contains premonitions that are full of meaning and conveys lessons that are set forth

"With such a lustre he that runs may read."

80 SOUTH STREET, NEW YORE CITY

\section{THE HUMAN SIDE OF THE DEVELOPMENT OF CHEMICAL INDUSTRY}

By G. W. Thompson

Numerous writers and speakers have called frequent attention to the great service which chemistry has rendered to humanity. In every field of industry she has been active, every product of man's labor has felt her magic touch. Modern civilization can be measured most accurately by considering the influence which chemistry has had upon industry and industrial operations. It is unnecessary here to tell what she has done. We are more concerned with the future than with the past, and judging the future by the past, the benefits which chemistry during the coming years will confer upon humanity will be infinitely valuable. On us, her votaries, is imposed the task of laying out the course of her progress, preparing and making the way easy for her and heralding her triumphant march. It is the purpose of this paper to indicate how this may best be done.

It should be perfectly obvious that the purpose of all industry is to satisfy the desires of human beings. This is as true of chemical industry as it is of any other industry. The chemist renders human service. $\mathrm{He}$ is a human being himself and his service to human beings makes him a part of a great democratic

1 Presented before the American Institute of Chemical Engineers, Chemists' Club, New York City, January 10 to $12,1917$. 
commonwealth in which every member is a factor in the development of the whole. The chemist is only a fraction in this commonwealth but the more he is organically a part of it the greater is his power of service. Like everyone else he does not exist by himself alone but is dependent for his existence upon every other human being that is a part of the social organism.

In the last analysis all of the relations between human beings are mental relations. The instruments of connection between human beings may be material but the relation itself is spiritual. In so far as the chemist renders service he does so by impressing himself on other people and affecting them either directly through personal contact or indirectly through the products of labor in the fabrication of which he has had a part. Human relationship, therefore, is the end toward which we are perforce all compelled to work. Each man must impress other people and he must in turn be impressed by them. There is no such thing as independence. We are all dependent, and in seeking for what we may nominally call independence we are simply shifting our dependence from one point to another. It is foolish to talk about being independent and it is unwise to seek independence, because it cannot be obtained. Still more important than this: it is best for us that we should not seek independence but that each one of us should seek to be dependent upon every one else, thereby conforming to the best conception of human relationships and to the economic law according to which the best service only can be rendered.

What we propose, therefore, is that the chemist should strive against anything that would tend to isolate him and separate him from his fellowmen. What we will try to show is the means by which he can avoid these tendencies; how he may more effectively integrate himself into the social organization.

\section{INTERFERENCES IN GROWTH OF CHEMISTRY}

Perhaps what we have in mind can best be visualized by considering here what has been believed by some to have interfered with the growth of chemistry in this and other countries. For instance, the cry has come from England that technically educated men have not been sought for as the occupants of high official and business positions. It has been claimed that a scientific education did not help towards social or public advancement, that in England a man with a classical education was sought after, not the scientific man. Assuming this to be so, it is perfectly clear that the advancement of the chemist in England has been retarded by a lack of public appreciation of the service which he renders or can render to the nation. What, then, is the chemist in England going to do about it? Apparently he is dissatisfied, which in itself is all right, but being dissatisfied does not alone change inexorable facts. In every chemical problem that confronts the chemist when facts stand in his way he does not get excited about them but seeks to surmount them by careful study and the devising of ways and means. This should be the attitude of the chemist in England, and by organized publicity-advertising if you will-he should seek to change public opinion so that it will accord to him a higher recognition.

That the English chemist is taking this view is indicated by a recent address by G. G. Henderson before the Chemical Section of the British Association for the Advancement of Science, Newcastle-on-Tyne, I9I6. In discussing the synthetic production of nitric acid from the air and the great advantage it would be to England, he laments that England has done nothing in the matter except to appoint a Committee to consider possibilities. Then he goes on to say: "This case is only too typical of many others. A number of different causes have contributed to bring about this state of affairs, and the responsibility for it is assigned by some to the government, by others to the chemical manufacturers, and by still others to the professors of chemistry. I think, however, it will be generally admitted that the root of the matter is to be found in the general ignorance of, and indifference to, the methods and results of scientific work which characterize the people of this country." $\mathrm{He}$ adds, however, that he thinks that the English leaders in science have done all that lay in their power to awaken the country to the inevitable and deplorable results of this form of "sleeping sickness" and that he believes that a brighter day is dawning and that if they rise to the occasion now, chemistry in that country will attain the position of importance which is its due.

Let us take another case. Germany has made great advances in chemistry. Some think that this is due to her system of education and probably this is partly true. Some think that it is due to the farsighted wisdom of public men. This, too, is probably partly true, but the real success of chemistry in Germany in my own opinion has been due to its greater popular appreciation. Historians have long since dropped the idea that kings and rulers in general amount to very much in the progress of a nation, and have adopted the broader conception that progress ultimately is in the people of a nation, their developing thoughts, their appreciation of the world that is about them.

The lesson to us in the United States is this-that if we wish chemistry to become a more potent factor in the industrial growth of our country we must take such steps as are necessary to bring about a popular appreciation of its value. Universities will help, government aid will help, but these too depend upon popular appreciation both in their beginning and in their execution; after all they are mere incidents to fundamental active causes. Create a demand for universities and universities will rise, as it were, over night; create a demand for governmental interest and governmental interest will come quickly and effectively, but demand is borne of popular appreciation.

\section{POPULARIZING CHEMISTRY}

Mr. Elwood Hendrick in an article that appeared not very long ago in one of our popular journals emphasized this point in urging the popularization of chemistry, and he expressed the thought that chemists would not come into what they believed to be their own until this was done. Mr. Hendrick's suggestion would indicate the advantage of chemists generally advertising their profession, not necessarily, however, in the form of paid advertisements, but in properly written articles for the popular press. The desirability of such a procedure properly carried out is fairly obvious, but subject to some limitations, which we will consider further on.

As an illustration of what we can accomplish in this direction I would refer to Robert Kennedy Duncan's writings (particularly his Chemistry of Commerce) as having been exceedingly efficient in popularizing chemical knowledge, and to the fact that Duncan's efforts in this direction probably resulted in the establishment of the Mellon Institute. As another example of a very commendable effort to popularize chemistry, I would refer to the Chemical Expositions, the second of which was held last September in the City of New York. When the first Exposition was proposed, many chemists expressed a great deal of doubt as to its wisdom and practicability, but as the time approached for the opening of the Exposition, its value to chemists became more clearly recognized and it received from them a very generous and hearty support. So successful was the first Exposition that immediately a second one was projected. This received even more generous support and two of our largest chemical societies decided to hold meetings at the same time. The public press has been fuil of matter descriptive of the Exposition itself and the accomplishments of chemistry thereby illustrated, and gave much space to the papers and discussions presented at the meetings of the two chemical societies. These Expositions were distinctly advertising in their character and great expenditures with the expectation of profitable return were made by the exhibitors themselves. 
Our National Departments of Agriculture and Commerce have done much in popularizing chemistry. The work Dr. Wiley started in the Department of Agriculture has extended the knowledge of chemistry in popular fields through the publication of numerous bulletins and leaflets. More recently the Department of Commerce has, through special investigators, been instrumental in increasing the knowledge of the relation of chemistry to industry. Similar work has been done to some extent by the Department of the Interior. All of these efforts have been of great advantage to chemists.

It seems hardly necessary that I should go further in emphasizing positive aspects of this phase of my subject. Let us consider now some of the criticisms that have been offered on work of this kind. The most general criticism is that when an attempt is made to popularize a science such as chemistry many unscientific statements will be made and true representations will oiten be incorrectly interpreted by the public. This is undoubtedly so. Erroneous ideas have been promulgated in this way, but the chance to err is not confined to popular presentations. We know that many errors have crept into scientific literature necessitating laborious effort later on for their correction. To err is human, and the danger that error may occur should not act as a preventive of public statements, whether these statements are made in the scientific or popular press

Another objection comes from those who hold that the profession of chemistry is of a very exalted character and that the serious chemist will not descend to ordinary popularizing effort. Our own Code of Ethics would prevent the chemist from advertising in a sensational manner, and requires the professional chemist to publish scientific papers in the technical journals before they are given to the popular press. It seems to me that our Code of Ethics is correct in this respect. We do not want to advocate sensationalism and we do want to build up our technical journals, but after the requirements of our Code have been complied with there still seems to be a field open to the chemist in which he can with perfect propriety popularize his science.

The advocates of the study of pure chemistry are also apt to look down upon this popularizing scheme. To them popular science is offensive and it may be that some of them can hardly be expected to sympathize with the views I am here presenting. The student of pure science is, however, almost in a class by himself. The utmost that he does in affecting the world's processes is by furnishing information, studies and generalizations to be applied by the practical chemist in furthering the interests of the entire world. Far be it from me to depreciate the value of the pure scientist. We all draw upon him for help in our practical efforts. It must be admitted, however, that he lies essentially outside of the plan that we are proposing. He indulges more or less in an esoteric culture and his light, though it is not hidden, is reflected to the world at large only by those who can practically direct that light to the illumination of ordinary things. In spite, therefore, of all that may be said against the popularization of chemistry, I am still convinced of the wisdom of such a purpose, because it is only by so doing that even the student of pure chemistry will be given an opportunity to carry on his studies. So firm is my belief in this that I would extend this effort so that it would reach and include the most humble members of society.

In order to present in picture form, as it were, the dependence of the chemist for his success upon the popular appreciation of chemistry, let me present the following sketch: A chemist makes what he believes is a discovery of great financial value. If he has money enough of his own he may be able to make that discovery a source of financial profit, but in so doing he will have to be something in addition to a chemist, for the largest part of his effort will be along lines which are essentially non-chemical, involving the organization of business, the advertising of the product or process, and its sale for use. In proportion as the public is capable of appreciating what he has accomplished, to just that extent will he make a financial success. Suppose, on the other hand, this chemist is not a man of means and wants to interest financial people in his discovery. As things are today he will first encounter skepticism, even ridicule, and if finally he is successful in having his discovery appreciated by financial interests, it will be because he has been able to convince them of its human aspects, and it may be that before he is through a great part of the value which he has seen in his discovery will have been absorbed by what the financial interests think is their proper return. The ordinary business man of today very naturally thinks that his business ability is more valuable than the technical ability of the chemist. He wants the lion's share. There is no use in closing our eyes to this fact. Many a poor inventor or discoverer has been so discouraged in his early efforts for recognition that he has been almost ready to drop his entire proposition. He says the blame lies on an unappreciating public, and this is true, but if it is true, how incumbent it is upon the chemist to make the public appreciative! He can do this only by studying the public, finding wherein the public should be educated, and recognizing all its limitations, working with wisdom toward the accomplishment of his purpose.

I think that I have said enough along this particular line to indicate to you my views as to what the chemist should do in the direction of trying to develop a popular appreciation of his work. If there is truth in what I say I am quite sure the open mind of the average chemist will discover it. If I am wrong he will soon find the vulnerable point in my argument. I would like now to pass to another aspect of this question, which relates more particularly to the chemist himself. What I have said so far deals for the most part with the attitude of mind of the chemist toward the public. What I propose to say now deals with the attitude of mind of the chemist towards himself. I have referred to a relation existing between the chemist and the public. In this relation there are two parties, the public on the one hand, and the chemist on the other. The problem before us is: What should the chemist do to develop and improve his attitude of mind towards himself? This is an exceedingly difficult subject, and if it were not that I am fortified by a belief in its importance, I would not dare to speak upon it. I cannot think of anyone holding a higher opinion of chemistry as a profession than I do, and all that I am saying is actuated by a profound belief that the chemist is only beginning now to climb the ladder that reaches to a power of service unequaled by any other profession.

The delicacy of this subject is such that I feel impelled to approach it in the form of questions. In putting these questions, let us consider first some facts, and then we can come to the questions themselves. Let us first consider the young chemist just leaving his college or university. Like all students graduating in various courses, he has yet to learn what business life really is. They think they know what it is, but we know that there is no college or university that teaches it. The difference between the chemist and most other graduates is noticeable in this: The chemist enters a more or less isolated laboratory; most of the others go directly into the commercial world. The chemist in this laboratory-be it analytical or research-is not dealing with people but with inanimate material things. $\mathrm{He}$ may stay in this laboratory a few months, a few years, or for his lifetime, as the case may be. He may be doing invaluable work, but-here is the question: Is he taking his proper place as a man in the world of men? Is he not too much isolated? Is he in his occupation gaining directly in his power over other men? Is his social instinct being developed or is it being retarded in its growth?

\section{SOCIAL RELATIONSHIPS}

If we think that laboratory chemists as a general class are taking their proper place in the world in which mind reacts upon 
mind, there is nothing more to be said; but if we think with his intelligence and education, the chemist has a mission outside of the indirect service he professionally renders to society, then our question leads us to urge that the barriers which ordinatily isolate the laboratory chemist should be broken down so that he can get out more into the pulsating business world. He may not be able to do this alone, and perhaps the duty devolves upon us; perhaps there are some of us who have it in our power to help bring about this liberation. If we want chemists to have a greater personal influence in the world, and by this we mean to include those chemists who are subordinate to us individually, is it not proper for us to ask ourselves whether at times we do not rather selfishly stand in their way? Cannot those of us who are employers of chemists give our employees more opportunity to become familiar with the commercial aspects of the work they do? If we do this, will they not become better and more profitable employees? In our dealings with non-technical men representing large business interests, could we not more regularly and persistently ask to be brought into contact with their chemists if they have them, thereby helping to pull them out of their seclusion? If we are asked to organize a laboratory in a commercial concern, could we not say that the work of the chemist would be greatly helped if it were so arranged that he would know the actual use to which his reports were to be put? Could we not do something in urging that the laboratories in which such chemists are expected to work should not be hidden away in inaccessible places? Could we not do many things suggested by the occasion to break the bonds which the young chemist, led by false hopes, may have often slowly forged? Is it not possible that with our colleges to-day filled with students of chemistry, these students should be advised against accepting positions of an isolated character?

You will see that I am basing my argument on two hypotheses, which are intimately related. One is that social relationship is one of the great purposes of life, and the second is that without such social relationship no individual can really be successfulin the development of any important enterprise. I have argued, therefore, that the chemist's success depends upon a social recognition of his worth, and second, that the chemist should enter into as broad a social relationship as possible. In popular terms one of these means that it pays to advertise, and the other means that the chemist should get out upon the broad highway.

I propose now to say a few words on the disadvantage which is sure to result from antagonism. I propose to advocate in all our dealings a conciliatory spirit. It would seem almost unnecessary to say that if the chemist is to advertise, he should avoid offending the persons who read his advertisements, just as it is perfectly obvious that the salesman who is trying to sell goods should not make himself persona non grata to the purchaser. A good salesman-and that is what we should all try to be in one form or another-subordinates his own views and makes them as inconspicuous as possible, but no less effective. What he tries to do is to find out the views of his customer so that he can furnish the customer with what he desires. I wonder if sometimes chemists are not a little more pugnacious than they should be. I sympathize with the feeling of an analytical chemist who will set his results up against the world and insist that he is right, but many years of experience have taught me that the chemist who does this without regard for the effect upon other chemists is doing a very foolish thing. I believe it is a good rule never to put anybody "in wrong." I believe it is far better, even in the case of commercial opponents, to help the commercial opponent out of his difficulties rather than to push him in deeper. Again, are we not at times a little too virulent in asserting our ideas respecting public officialsadministrative, legislative and judicial. They are human beings, just as we are, they are representatives of the whole people, and if their views differ somewhat from ours, is it not very much better to work patiently and steadily to change their views, directing them into constructive paths, rather than to confirm them in their views and drive them to unwise extremes by opposing them vigorously?

Let 11 take as an illustration a subject on which perhaps chemists are divided at the present time, although the division may be by no means equal. Many chemists are seeking to have our National Government help the chemical industry to become more firmly established in this country. Some think it can be done by subsidies, others by protective tariffs, others by embargoes, and so on. Now I would not argue in this meeting for or against any of these propositions. I simply say that if you are in favor of any one of them it is unwise because he opposes you to incur the antagonism of any public official, even if he be of an opposite political faith. Practically all public officials have their ears to the ground; they are trying to find out what their constituents want, and no one should blame them for this. In so far as they are representatives they are doing only their duty. It is perfectly proper for us to try to convert a public official to our way of thinking. It is still more proper for us to try to convert the people he represents to our way of thinking, but I consider it the height of foolishness to attribute to public officials dishonest purposes, ignorance, stubbornness and all the other sins of commission and omission. My point is very clear - such accusations do not lead you anywhere but into trouble.

I believe firmly that the obstacles which we meet in our social acts in endeavoring to get our plans consummated do not differ essentially from the obstacles which the chemist meets in the ordinary routine of his work. If he finds a chemical reaction is not progressing satisfactorily, he does not close his eyes to this fact and denounce some devil or anthropomorphic god because it has interfered with his work. He tries to find the cause of the trouble and remove it. So I say that if you have social obstacles to overcome, find their cause and remove it, bearing in mind that there is no easy way by which this can be accomplished-in fact that there is only one way-education backed by good-fellowship.

\section{HUMAN EFFICIENCY}

We have heard in recent years a great deal said about efficiency, it may be that some foolishness has been uttered. The word "efficiency" is used in various ways. We have the efficiency of a process considered by itself; we have this efficiency as compared with other processes; we have mechanical, chemical and human efficiency. I am interested primarily in this paper in human efficiency. What does it mean? Broadly speaking it means coöperation without friction. Perhaps we should say that coöperation cannot be had with friction. Of course it would be absurd for me to attempt to solve the eternal problem of human friction in a paper of this kind. All I can do is to indicate some ways by which it can be reduced. While the realization of frictionless humanity is far away, symptoms of it have certainly appeared at times. Efforts in the direction of reducing human friction conspicuously numerous at this time are to be found illustrated in factory welfare work, Workman's Compensation Acts, pension systems, etc. All of these have been justified by the increase in human efficiency they have produced. A man whose welfare is of no account is not a good workman.

Human efficiency, however, demands right men in the right places. The difficulty that the employer experiences is in knowing whether he is picking the right man for the place or not. If the man has been educated rightly the employer is better able to form an opinion. Particularly is this true regarding foremen and the higher grades of labor. Graduates of such institutions as give technical education are made more nearly right for places in chemical and other industries. More general industrial education such as that being advanced in some states will undoubtedly add to human efficiency. Even then the making of a 
man suitable for a given position comes after he comriences employment and is largely the work of the employer himseli.

Industries do not merely require men, however. they are complicated machines of which the men form a part. The proper fitting and adjusting of these machines to the men employed is the big problem only partly worked out as yet. Each industry has its own requirements, these requiremerits continually changing with the growth of society. Who has not been face to face with the requirements of an industry? These requirements are almost vitalized by competition. Industries come and industries go, they are planted and they are reaped, but their volume increases from year to year. We must not, however, allow ourselves to think of industries and industrial processes as though they were other than inanimate things. We should not waste our tears over their rejection when they are worn out, provided others take their place. This is growth-the sloughing off of the old and the putting on of the new.

\section{NEW PROCESSES}

The chemical engineer has a great deal to do with the development and administration of new processes. Many an old fogy has damned the chemical engineer, who has rendered his processes and his equipment antiquated and idle. The mechanical engineer also has received his malediction. We are sorry for the old fogy and would, if it were possible, provide insurance for him, but we would do nothing to retard the fate of his equipment.

The development of a new process is the result of many separate factors. New processes are like the waves of the sea; they cannot rise much higher than the level of the sea itself. They rest on general industrial growth and are not much above the level of that growth. This is true of all processes, chemical processes included. Their growth depends upon the growth of the mechanical art, its method of fabrication, and all the materials that enter into construction. It depends upon highly developed foundry practice, mining, building construction, farming and transportation, and last, but not least, all those branches of human development which are manifested in the home, social organization, governments and international relations. I emphasize this human factor because so many processes have had to wait years for the time to ripen for their introduction, indicating, in other words, that not alone should our endeavors be directed to the development of processes, but they should also be directed in a general effort to accelerate the coming of the fullness of time. The fullness of time means that the social level has been sufficiently raised.

New processes are of two kinds: first, those which provide improved methods for making old and well-known products, and second, those which involve the making of new products to take the place of old, or new products which serve entirely new purposes. A new process which is intended to provide methods for making an old product, if it is to be successful, must involve economy of some sort, economy of material, investment, time or labor. Necessity creates the demand for such new processes. Competition, domestic and foreign, is the impelling force. The wise manufacturer recognizes that the development of a new process may be his salvation. It is impossible in this paper to discuss all the demands which compel the invention of a new process. We will discuss only the human or labor element.

\section{KEEPING DOWN LABOR COSTS}

If labor here in the United States is higher in price per unit of product than it is abroad, it is manifest that with free competition the manufacturer must so modify his process that this item in cost will not militate against him. He may not be willing to modify his process, and his first instinct may be to limit the competition by a protective tariff or some similar restrictive measure. One objection to this, except as a last resort, is that it removes some of the pressure which makes for improvement of process. We may dislike the pressure but we know after all that it is a good thing. We cannot allow any. thing to interfere with such pressure as makes improvement necessary. Such improvement may be possible. It is mucl wiser to insist that it is possible than to insist that it is not. Success is of ten accomplished by doing what is apparently impossible, but assuming that the manufacturer cannot get the protection he wants, how will he go about improving his process? We will offer only a few suggestions.

\section{ADVANTAGES OF MANUFACTURING IN LARGE UNITS}

The first consists in manufacturing in large units. By this means overhead charges are reduced and materials can be handled more cheaply by mechanical means, thereby either directly or indirectly reducing the cost of the labor factor. In this direction it would appear that the United States has been pre-eminently successful; there is probably no country in the world which equals us in this line of development. The second consists in subdivision and specialization of labor. It is obvious to all that it is through this method that most of our industries in this country have been successful. The third is radical development of process. If we take a given process and consider all of the operations, step by step, we are able tentatively to classify these steps into two kinds-the essential and the apparently necessary. The apparently necessary step is not by any means an essential step. An apparently necessary step is one that the state of the art has not eliminated. An essential step is one that we feel justified in saying cannot be eliminated, no matter what the state of the art is. By a radical development of process it may be possible to eliminate apparently necessary steps. The burning down of a house in order to roast a pig was in the mind of the Chinaman of fiction an apparently necessary step. It was, however, eliminated by the Efficiency Engineer of his day. Fourth, by doing by machinery what was theretofore done by labor. An essential step in a process may still appear essential, although instead of performing the step by manual labor it is done by machinery. This much does not involve the elimination of a step. Doing by machinery what was theretofore done by labor is the obvious method of reducing labor costs. It ustally entails, however, additional cost for investment, power, and repairs, and also the employment of a higher class of labor. It is perfectly obvious that where labor is cheap machinery is unnecessary, but that where labor is high, competition compels the use of machinery, and that this is the proper and natural order of things.

\section{MECHANICAL EFFICIENCY MUST LEAD TO HUMAN EFFICIENCY}

This is perhaps to you a somewhat academic presentation of the methods to be followed in studying how a process can be improved. If I should go into the methods by which new processes for making old or new products might be worked out, it is probable that this study would be still more academic; and I will not attempt here to touch upon that branch of the subject. What you may consider academic in what I have said, however, has a very practical bearing upon the general subject I am endeavoring to present. As I have already indicated, I am interested in human efficiency. Mechanical efficiency that does not lead to human efficiency is of rare occurrence. Considered in the most general economic terms it is doubtful if it ever occurs. It is natural for us to think of human efficiency as a means rather than an end, but I would reverse this relation and ask you to consider human efficiency as more of an end than a means. It is desirable that we should have high-priced labor because high-priced labor usually means greater intelligence and higher character.

A more highly developed social organism is one of the noblest objects for which one can work, and all efforts spent on the de- 
velopment of its parts is well worth while. If you believe with me that an appreciative public is necessary for the proper growth of the chemical industry, you will also agree that we need a public which shall have the power of appreciation which can come only as a result of the general raising of the level of social conditions.

The chemist by working for improvement in processes involving a saving of labor, and at the same time involving the employment of a better grade of labor is contributing his part to the better development of a high social organism. If the chemist, however, simply endeavors to improve a process without regard to the possibility of that improved process involving the employment of a higher type of labor, then his work is incomplete. It is true that his process may with cheap labor be able to manufacture products which are used by the entire community, and which consequently can be sold at a reduced figure and thereby benefit society, but many difficulties will lie in his path if he does not at the time that he reduces the quantity of labor necessary in the process, also create a demand for a higher quality. I therefore ask those of you who are engaged in the development of processes, such development being forced by competition and the requirements of the industry, to consider whether it would not be better for you to put your mind in the attitude that in your development of process you may possibly be able to get better results by the use of more intelligent and higher priced labor than you could by sticking to low-priced labor and possibly handicapping yourself and your process and preventing its fullest development.

\section{CONCLUSIONS}

I have endeavored in this paper to present several aspects of a very large and important subject. Some parts of it may appeal to you and other parts may excite your opposition. In the main, however, I believe all of these parts are related to each other consistently and logically. If you believe, as I do, that a better social organism is the highest purpose for which anyone can work, you will accept what I have said and include in the proposition many extensions on which I have not touched. If, however, your minds are more practical, I think you will accept many of the things I have presented to you purely on account of their practical value. Therefore from whatever standpoint you approach the subject, am I not correct in stating that practical business success in all lines of business, including those involving the use of chemistry, is dependent upon popular appreciation, is dependent upon social growth, on which the power of appreciation rests, and that everything which tends to increase the power of appreciation helps appreciation itself, and that anything that increases appreciation increases the chance of success of a business enterprise? Or to put it negatively, anything that interferes with an increasing power of appreciation, anything that tends to prevent appreciation or creates those antagonisms which operate against appreciation is pretty sure to hinder the growth of a business enterprise.

If this fundamental proposition is accepted, we can readily see how important it is for the chemist in attempting to build up chemical industry in the broad sense to do everything in his power to raise the general level of human knowledge and education and of social conditions, for it is that level that determines the power of appreciation. Assuming this power of appreciation to exist and to be growing in strength, you will also, I think, agree with me that the chemist should do everything in his power to create a greater appreciation of the value of chemistry in solving the problems of industrial life, for it is only through such appreciation that the chemist himself will be able to exert fully that ability for service which we all believe he possesses. But if the chemist is to impress himself on the public through legitimate advertising, should he not also endeavor to develop that attitude of mind which makes him con- tinually a factor in social growth? Should he not break away from all influences that tend to isolate him, and that, if they do not make him a peculiar being, at least have the effect of preventing him from having the fullest influences over others? Should we not do everything in our power to broaden the horizon of the chemist, to increase, as it were, his circulating power in the social organism? Should we not, as chemists, by very simple methods do all we can to pull chemists individually out of all such surroundings which tend to narrow and handicap them?

Now having done all of these things, should we not go a step further and recognize the peculiar position which the chemical engineer occupies in the development of chemical processes? Our minds naturally operate discontinuously. We think of a chemical process and its development as an independent thing, as though it were not a part of all of the other processes continually operating in society. We think that with the development of a process our work is ended; we think that with cheaper manufacture of given products we can sit down with satisfaction and consider our efforts successful. But philosophers tell us that there is no such thing as discontinuity, that everything runs into everything else continuously and is a part of a complete whole. Some fancifully have said that if a man could destroy a single atom, the universe would fall to pieces. This is fanciful but it expresses a true conception. There is such a thing as solidarity-not the solidarity of labor, not the solidarity of industry, but more surely the solidarity of society. All things operate in circles. We have continuous production and continuous consumption, in which material things circulate around and around, never completely stopping. This is so of all human affairs. Effects are unending. All the ends we work for are but the means to other ends. The development of a process was the end yesterday, but to-day it becomes a means-a means by which the social level is raised, which in turn becomes a means by which other processes are developed.

This is why I have expressed my opinion that in the development of a process it can hardly ever be said to be complete unless it results in the substitution of quality of labor for quantity, whenever such a development has for its purpose the saving of labor. Development of a better quality of labor is essential if we are seeking broadly to increase the power of appreciation on the part of the public. It would be manifestly foolish for me to advocate that chemists should seek to impress Hottentots and Fiji Islanders with the power of service in chemistry. It would take centuries of education to bring them up to the point where we of America are to-day. It is equally foolish to think that we can expect as much appreciation from common labor as we can from intelligent labor. In saying this I make the assumption with which I hope you will agree-that every member of society, the ignorant and the wise, the poor and the rich, the bad and the good, the sick and the well, are all integrally a part of society and each one has his individual influence in determining the average social level which measures the power of appreciation.

I have endeavored in this paper to avoid taking any position which is negative in its character. I do not believe that there is such a thing as a negative force; the nearest we come to it is inertia. I have endeavored to make positive suggestions which I submit for your consideration with the daring hope that these suggestions may find lodging places, temporarily it may be, in your minds, and if, after these ideas have stayed in your minds for a short time, they then take their flight, I have the still more daring hope that after you have forgotten them, they may, though unconsciously to you, have left some faint imprint.

National Lead Company

129 YORK STREET, BROOKLYN, N. Y. 